\title{
Upscaling reflectance information of lichens and mosses using a singularity index: a case study of the Hudson Bay Lowlands, Canada
}

\author{
T. Neta ${ }^{1}$, Q. Cheng ${ }^{2,3}$, R. L. Bello ${ }^{3}$, and B. Hu ${ }^{2,3}$ \\ ${ }^{1}$ Department of Earth and Atmospheric Sciences, University of Alberta, Edmonton, Alberta, Canada \\ ${ }^{2}$ Department of Earth and Space Sciences and Engineering, York University, Toronto, Ontario, Canada \\ ${ }^{3}$ Department of Geography, York University, Toronto, Ontario, Canada
}

Received: 25 March 2010 - Published in Biogeosciences Discuss.: 19 May 2010

Revised: 5 August 2010 - Accepted: 18 August 2010 - Published: 27 August 2010

\begin{abstract}
Assessing moisture contents of lichens and mosses using ground-based high spectral resolution spectrometers (400-2500 nm) offers immense opportunities for a comprehensive monitoring of peatland moisture status by satellite/airborne imagery. This information may be valuable for present and future carbon balance modeling. Previous studies are based upon point measurements of vegetation moisture content and water table position, and therefore a detailed moisture status of entire northern peatlands is not available. Consequently, upscaling ground and remotely sensed data to the desired spatial resolutions is inevitable. This study continues our previous investigation of the impact of various moisture conditions of common sub-Arctic lichen and moss species (i.e., Cladina stellaris, Cladina rangiferina, Dicranum elongatum, and Tomenthypnum nitens) upon the spectral signatures obtained in the Hudson Bay Lowlands, Canada. Upscaling reflectance measurements of the above species were conducted in the field, and reflectance analysis using a singularity index was made, since this study serves as a basis for future aircraft/satellite research. An attempt to upscale current and new spectral reflectance indices developed in our previous studies was made as well. Our findings indicate that the spectral index $C$. rangiferina is to a lesser amount influenced by scale since it has a small $R^{2}$ values between the log of the index and the log of the resolution, reduced slopes between the log of the index and the log of the resolution, and similar slopes between log reflectance
\end{abstract}

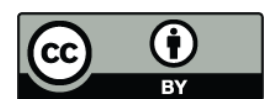

Correspondence to: $\mathrm{T}$. Neta (talineta@gmail.com) and $\log$ resolution $(\alpha)$ of two wavelengths employed by the index. Future study should focus on concurrent monitoring of moisture variations in lichens and mosses both in situ and from satellite and airborne images, as well as analysis of fractal models in relations to the upscaling experiments.

\section{Introduction}

Spatial scaling of land surface processes has been acknowledged as one of the most complicated and challenging issues in environmental sciences (Chen, 1999). Scaling refers to the use of information available at one scale to derive processes that occur at a finer (down-scale) or a coarser (up-scale) scale (Ehleringer and Field, 1993; El Maayar and Chen, 2006). Downscaling is generally required for the use of available information at a given resolution to a system where some processes operate at a finer resolution (El Maayar and Chen, 2006). When a desired operational spatial resolution for mapping a variable is coarser than the size of the ground data sample and the size of the remotely sensed data pixels, upscaling or aggregation of the ground and remotely sensed data is required; that is, there is a need to infer spatial information from a finer to a coarser spatial resolution (Wu and Qi, 2000).

Since land surfaces are typically heterogeneous and nonlinear systems, in the process of upscaling, information at one spatial resolution may deduce information at another (Chen, 1999; Ehleringer and Field, 1993; Simic et al., 2004; Williams et al., 2008). Therefore, it is important to examine the relationships between fine and coarse scales. With

Published by Copernicus Publications on behalf of the European Geosciences Union. 
Table 1. Current and new spectral indices for detection of vegetation moisture content. Ref represents reflectance values in percentage (the wavelengths units are in $\mathrm{nm}$ ), and min and avg refer to minimum and average, respectively. The mean $R^{2}$ values (of all sites and dates) between the $\log$ of these spectral indices and the log of the spatial resolution are in the following increasing order: $C$. rangiferina (0.44), MSI (0.49), simple ratio (0.52), NDII (0.54), C. stellaris (0.55), NDWI (0.55), and WBI (0.67).

\begin{tabular}{lll}
\hline Index & Formula & Reference \\
\hline WBI & $\operatorname{Ref}_{920} / \min \left(\operatorname{Ref}_{960-1000}\right)$ & Penuelas et al., 1997 \\
Simple Ratio & $\operatorname{Ref}_{1600} / \operatorname{Ref}_{820}$ & Ceccato et al., 2001 \\
MSI & $\operatorname{avg} \operatorname{Ref}_{1550-1750} / \operatorname{avg} \operatorname{Ref}_{760-800}$ & Vogelmann and Rock, 1986 \\
NDII & $\left(\operatorname{Ref}_{820}-\operatorname{Ref}_{1600}\right) /\left(\operatorname{Ref}_{820}+\operatorname{Ref}_{1600}\right)$ & Hardisky et al., 1983 \\
NDWI & $\left(\operatorname{Ref}_{860}-\operatorname{Ref}_{1240}\right) /\left(\operatorname{Ref}_{860}+\operatorname{Ref}_{1240}\right)$ & Gao, 1996 \\
C. rangiferina & $\left(\operatorname{Ref}_{1080}-\operatorname{Ref}_{1480}\right) /\left(\operatorname{Ref}_{1080}+\operatorname{Ref}_{1480}\right)$ & Neta et al., 2010a \\
C. stellaris & $\left(\operatorname{Ref}_{900}-\operatorname{Ref}_{1470}\right) /\left(\operatorname{Ref}_{900}+\operatorname{Ref}_{1470}\right)$ & Neta et al., 2010a \\
\hline
\end{tabular}

no appropriate attention, major errors can be made in the upscaling process (Chen, 1999; Williams et al., 2008). Upscaling uncertainties are defined as variances of spatial data that are associated with ground data, images, and maps. When spatial data are scaled up from finer to coarse scales, the uncertainties will be propagated to the final products (Wang et al., 2004). Chen (1999) suggests that major causes for the errors in a surface parameter retrieved at coarse resolutions are associated with the averaging process of a radiative signal received by a sensor. Transferring algorithms from one resolution to another without incurring considerable errors is one of the greatest challenges in remote sensing (Chen, 1999).

Our previous studies (Neta et al., 2010a, b) examined the spectral response of common sub-Arctic lichen and moss species (i.e., Cladina stellaris, Cladina rangiferina, Dicranum elongatum and Tomenthypnum nitens) to varying field moisture conditions, and its relation to the water table position, in the Hudson Bay Lowlands, Canada (a northern peatland). Since plants' moisture content and the water table position have a great impact on greenhouse gas emissions, they are important variables in carbon balance studies. However, these studies are based upon point measurements (Bubier et al., 1997; Walter et al., 2001). Point measurements of vegetation moisture content, as well as water table position are quite informative. However, these measurements cannot describe moisture conditions of northern peatlands over large spatial scale. Consequently, changes in northern peatlands moisture conditions, and accordingly variability in the watertable position, are not acknowledged (Walter et al., 2001).

Since it is fairly complex and costly to conduct comprehensive inter-annual moisture measurements across entire peatlands, other inexpensive, large spatial scale methods should be considered. As established by Hay et al. (1997), remote sensing may be useful in distinguishing and evaluating temporal and spatial variations in moisture status of northern peatlands. While a fairly small point size is normally measured on the ground, airborne and satellite data have greater spatial resolutions. Consequently, upscaling ground and re- motely sensed data to the desired spatial resolutions is inevitable. Therefore, in this study we present the results of our upscaling reflectance experiments in the field, in continuation to our laboratory reflectance measurements, presented in our previous studies (Neta et al., 2010a, b). The objective of the upscaling experiments includes the examination of the reflectance obtained at different spatial resolutions in order to upscale the information derived by current spectral indices and our new species specific spectral indices developed in our previous studies (Table 1; Neta et al., 2010a, b). The methods and results of this study can be applied in other environments and may serve as a basis for future airborne/satellite based measurements.

\section{Study area}

The study area is located in the Hudson Bay Lowlands, approximately $20 \mathrm{~km}$ southeast of the town of Churchill, and $2.4 \mathrm{~km}$ southwest of the Churchill Northern Studies Centre (CNSC), in north-eastern Manitoba, Canada $\left(58.72^{\circ} \mathrm{N}\right.$, $93.83^{\circ} \mathrm{W}$, Fig. 1). The Hudson Bay Lowlands is the second largest contiguous peatland worldwide (after the West Siberian Lowlands in Russia), that covers approximately $324000 \mathrm{~km}^{2}$ of land, largely to the south and southwest of the Hudson Bay (Fig. 1). The terrain is flat, poorly drained and underlain by marine silts, clays and permafrost. Wetlands embrace $50-75 \%$ of the Hudson Bay Lowlands and fall into two broad classes; (1) fens comprising primarily sedge (Carex spp.) and brown moss, and (2) raised bogs supporting lichen-moss-heath vegetation (Ricketts et al., 1999).

Continued uplifting of the land surface due to isostatic rebound creates belts of raised beaches. This isostatic rebound is a result of the crust being depressed from the weight of the Laurentide ice sheet during the most recent Wisconsin glaciation (approximately 20000 years before the present day). The tundra vegetation near the present day coastline gives way to isolated copse of white spruce and larch, and then open crown white and black spruce forest as one moves 


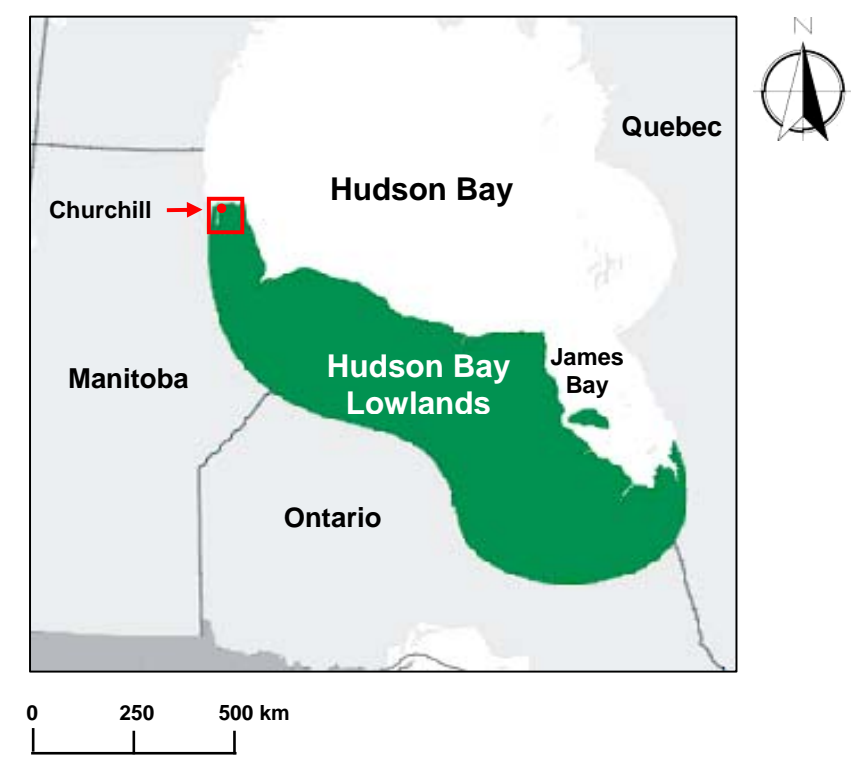

Fig. 1. The location of the study area (red square) and the town of Churchill (red point) in the Hudson Bay Lowlands, north-eastern Manitoba, Canada. The Hudson Bay Lowlands is the second largest contiguous peatland worldwide (after the West Siberian Lowlands in Russia), where wetlands embrace $50-75 \%$ of the area (Ricketts et al., 1999). The green area in this map represents the contiguous peatland that covers approximately $324000 \mathrm{~km}^{2}$ of land (modified from the source map of University of Maine Canadian-American Center Cartography, 2005).

inland. The thick underlying peat deposits form peat plateau made up of high center ice-wedge polygons which cover approximately $12000 \mathrm{~km}^{2}$ within the province of Manitoba (Ricketts et al., 1999).

\section{Upscaling experimental design}

Upscaling spectral measurements using the ground-based Ocean Optics spectrometers USB4000 (spectral coverage of $400-900 \mathrm{~nm}$, and spectral sampling intervals of $0.2 \mathrm{~nm}$ ) and NIR256 (spectral coverage of 900-2400 nm and spectral sampling interval of $6.8 \mathrm{~nm}$ ) were conducted in the field in the summer of 2007 ( 30 June to 19 August). To avoid the noise observed in the edge of the spectrum (as a result of low signal to noise ratio), we refer to the $400-850 \mathrm{~nm}$, and $1000-2300 \mathrm{~nm}$ regions, only. These upscaling experiments were conducted in days with clear clouds sky conditions, to obtain steady illumination conditions, which are required for the conversion of spectral measurements to absolute percent reflectance (Sanderson et al., 1998). It should be noted that clear clouds sky conditions are rather exceptional in this study area, and therefore, only a small number of days were available for accurate upscaling spectral measurements in the field. Furthermore, the sensor was leveled in nadir position above the target, to reduce inaccuracies in spectral readings. However, wind conditions in this study area are relatively unstable, and that might influence the accuracy of the results as well (i.e., decrease the signal to noise ratio, or saturate the reflectance).

Prior to each measurement, reference spectra from a highly reflective (99\%) Lambertian spectralon white reflectance panel ("white reference") was collected in order to convert spectral measurements to absolute percent reflectance (Eq. 1). For this purpose, a measurement of the noise inherent in the instrument ("dark") was made with no illumination (Eq. 1).

To determine the canopy spectral reflectance as an absolute percentage of the incident light, the following formula was applied (following Sanderson et al., 1998):

Reflectance $(\%)=\frac{\operatorname{Rad}_{t} \text { arg et }-\operatorname{Rad}_{\text {dark }}}{\operatorname{Rad}_{\text {white }}-\operatorname{Rad}_{\text {dark }}} \times 100$

where, $\operatorname{Rad}_{\text {target }}, \operatorname{Rad}_{\text {dark }}$ and $\operatorname{Rad}_{\text {white }}$ represent the radiance spectra of the target, dark, and the white reference, respectively.

Four representative sites (named 101, 102, 103, and 106) were selected in the raised bog area, near Churchill, Manitoba $\left(58.72^{\circ} \mathrm{N}, 93.83^{\circ} \mathrm{W}\right)$ for the upscaling experiments. At a constant height $(2.20 \mathrm{~m})$, various scales were employed by modifying the sensor's field of view from $3^{\circ}, 8^{\circ}, 10^{\circ}$, and $14^{\circ}$ to $24.8^{\circ}$. As a result, the spatial resolution (i.e., the diameter of the circle) was changing from 11.7, 31.3, 39.2, 55 to $98.5 \mathrm{~cm}$, respectively.

\section{Upscaling reflectance using a singularity index}

As established by Cheng (2006), in multifractal models the singularity exponent is an index quantifying the scaling invariance property. In this study, the singularity index is related to the spectral reflectance properties Ref, obtained at different spatial resolutions $\varepsilon$, and defined as

$\operatorname{Ref}(\varepsilon)=c \varepsilon^{\alpha}$

where $c$ is a constant and $\alpha$ is the exponent. The density function introduced by Cheng (2008) $\rho(\varepsilon)$ can be defined as

$\rho(\varepsilon)=\operatorname{Ref}(\varepsilon) / \varepsilon^{E} \sim c \varepsilon^{\alpha-E}$

where $E$ is the dimension of the pixel (e.g., $E=2$ for a two dimensional map). The value of the singularity index $\alpha$ varies within a finite range from $\alpha_{\min }$ to $\alpha_{\max }$. The index $\alpha$ can be estimated by the least squares method to fit a straight line to a set of values of $\operatorname{Ref}(\varepsilon)$ against $\varepsilon$ in $\log -\log$ space. The values $\alpha$ and $\log (c)$ can be taken as the slope and the intercept of the straight line, respectively. The standard error and correlation coefficient involved in the estimation can be calculated from the least squares fitting and these indices can be used for evaluating whether power-law relationships exist (Eqs. 2 and 3). The power-law relations usually hold true 


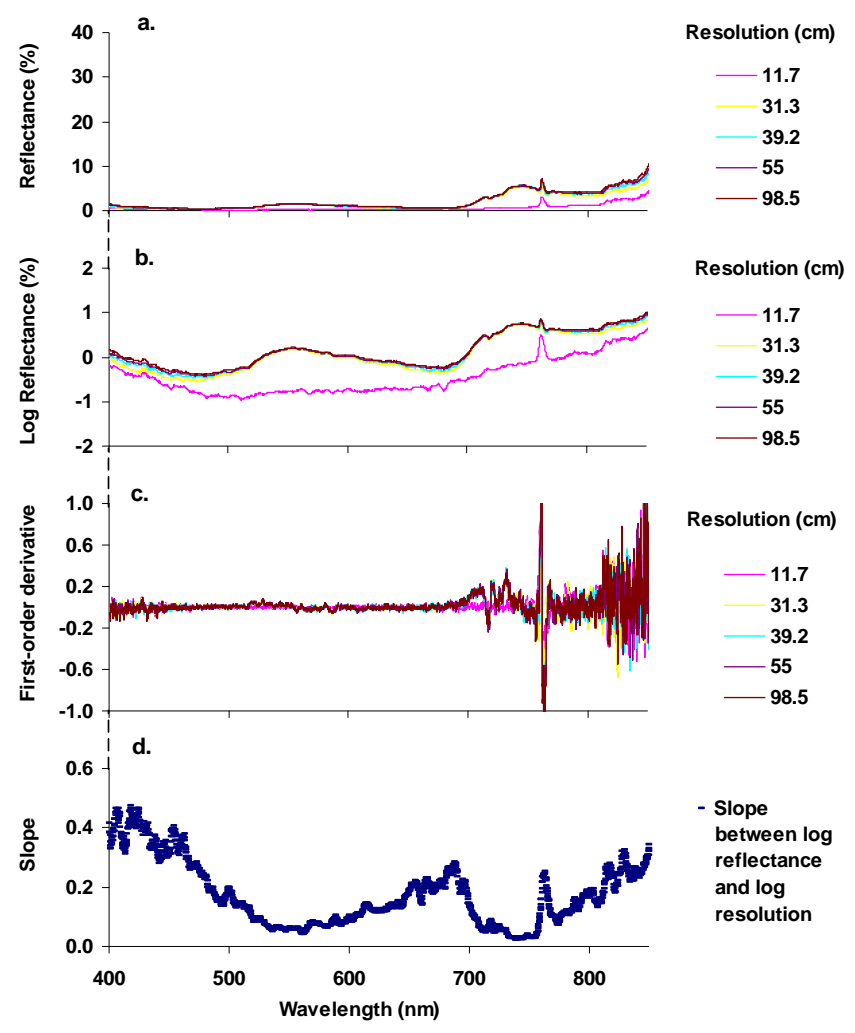

Fig. 2. Data obtained in 12 August 2007, in site 106, using the wavelength range of $400-850 \mathrm{~nm}$, at various spatial resolutions; (a) Reflectance. (b) Log reflectance. (c) First-order derivative. (d) slope between log reflectance and log resolution.

for a certain range of spatial resolutions, denoted as $\left(\varepsilon_{\min }\right.$, $\left.\varepsilon_{\max }\right)$, and the singularity index is the average values for the smallest pixel with the size of $\varepsilon_{\min }$. The singularity index estimated from Eq. 3 has the following properties (Cheng, 2008):

1. $\alpha=E$, if $\rho(\varepsilon) \sim$ constant, independent of pixel size $\varepsilon$.

2. $\alpha<E$, if $\rho(\varepsilon) \sim c \varepsilon^{\alpha-E}$ is a decreasing function of $\varepsilon$.

3. $\alpha>E$, if $\rho(\varepsilon) \sim c \varepsilon^{\alpha-E}$ is an increasing function of $\varepsilon$.

Cases 2 and 3 correspond to singular situations in which the density function $\rho(\varepsilon) \rightarrow \infty$ or $\rho(\varepsilon) \rightarrow 0$ as $\varepsilon \rightarrow 0$. In the case of $\rho(\varepsilon) \rightarrow \infty$, it implies that within the pixel of size $\varepsilon$ there is an anomalously high density (Cheng, 2008).

The singularity index usually has finite values around $E$. For a conservative multifractal measure, the dimension of the set with $\alpha=E$ is close to $E$ (box-counting dimension), which means that the areas on a map with continuous background values occupy the greatest part of the map. The dimensions of the other areas with $\alpha \neq E$ are given by the fractal spectrum function $f(\alpha)<E$. This implies that the areas with singular values (anomalies) are relatively small in comparison with the areas with nonsingular values (background

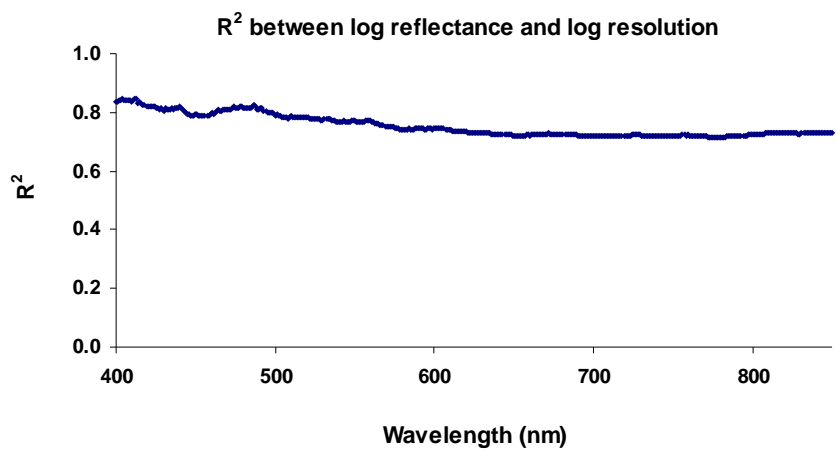

Fig. 3. $R^{2}$ between $\log$ reflectance and $\log$ resolution between $400-$ $850 \mathrm{~nm}$, obtained on 12 August 2007, in site 106 ( $n=5$, significance level $<0.05$, and critical value $R^{2}>0.65$ ).

values). Based on a statistical point of view, the majority of values on the map where $\alpha \sim E$ follows either normal or lognormal distributions, whereas the extreme values on the map with singularity $\alpha \neq E$ may follow Pareto Distributions (i.e., power law probability distribution) (Cheng, 2008).

Equation 3 shows that the average density function defined in a pixel size $\varepsilon$ follows a power-law relationship with the scale unit (spatial resolution of size $\varepsilon$ ). The exponent $\alpha-E$ characterizes the local singularity of the function - how the values changes as the scale unit decreases. Once $\alpha \neq E$, the density is dependent on the scale unit. In this case, the constant $c$ becomes a useful quantity independent of pixel size and remains unchanged when pixel size reduces. This value of $c,\left(c=\operatorname{Ref} / \varepsilon^{\alpha}\right)$ can be considered as the measure of the density $\rho(\varepsilon)$ in the space of $\alpha$ dimension; for example, if Ref stands for spectral reflectance (\%) with spatial resolution of size $\varepsilon(\mathrm{cm})$, then $c$ has the unit $(\% / \mathrm{cm})^{\alpha}$. It becomes the ordinary density value in nonsingular locations where $\alpha=2$. This decomposition ensures that any complex measure decomposes into an absolutely continuous measure and a singular measure (Cheng, 2008).

To examine changes in reflectance at various scales, Figs. $2-5$ are presented as a representative example (obtained at site 106 on 12 August 2007), while our ultimate objective is to upscale current reflectance indices, along with our new developed indices (Table 1; Neta et al., 2010a, b). The reflectance (\%), log of the reflectance, and the first-order derivative of the reflectance obtained at various scales, along with the slope (i.e., singularity index $\alpha$ ) between the log of the reflectance and the log of the spatial resolution, and the coefficient of determinations $\left(R^{2}\right)$ between the log of the reflectance and the $\log$ of the spatial resolution, were plotted (Figs. 2-5). It should be noted that the slope between the $\log$ of the reflectance and the log of the spatial resolution between $400-850 \mathrm{~nm}$ (Fig. 2) was calculated for the greater scales only (i.e., $31.3 \mathrm{~cm}$ to $98.5 \mathrm{~cm}$ ), since the reflectance obtained of the $11.7 \mathrm{~cm}$ resolution is an outlier, as seen in Fig. 2. The log of the reflectance is presented since the log 


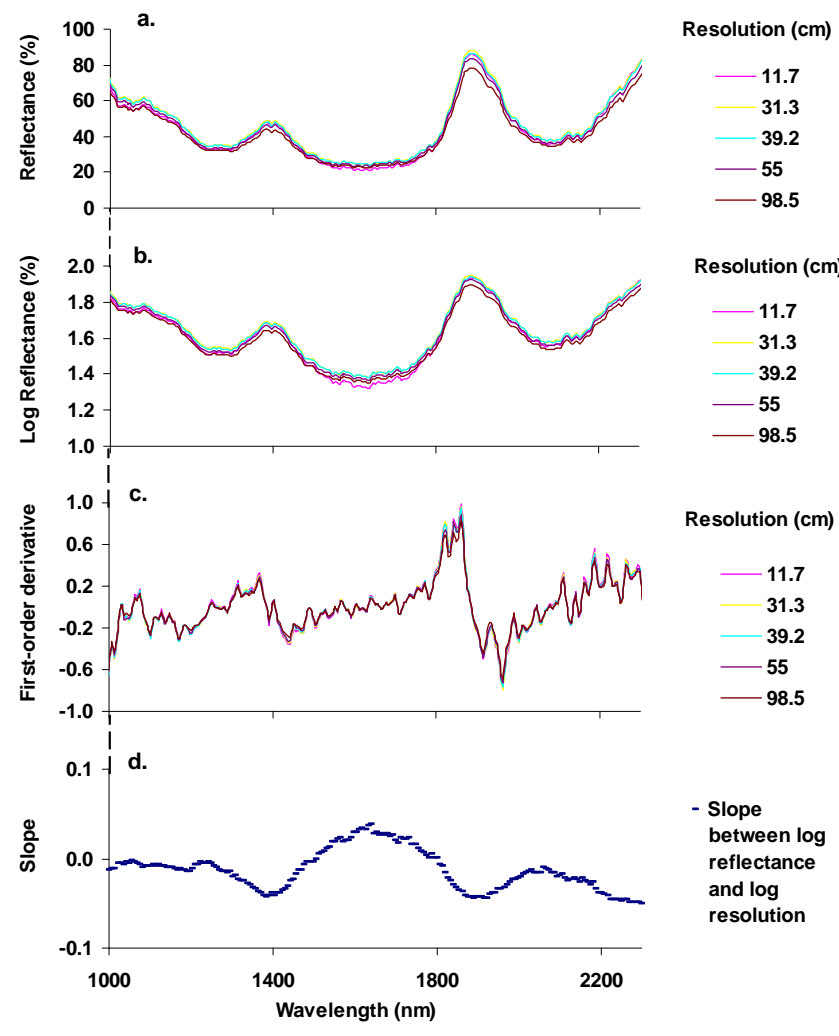

Fig. 4. Data obtained in 12 August 2007, in site 106, using the wavelength range of $1000-2300 \mathrm{~nm}$, at various spatial resolutions; (a) Reflectance. (b) Log reflectance. (c) First-order derivative. (d) slope between log reflectance and log resolution.

function emphasizes the scale, and thus, variations that are difficult to distinguish within the reflectance curve are better distinguished by the log reflectance diagram. The singularity index $\alpha$ may imply on changes in reflectance as a function of different scales, and whether the reflectance is influenced by scale. $R^{2}$ values between the $\log$ of the reflectance and the $\log$ of the spatial resolution are also presented, since it can be used for evaluating whether power-law relationships exist. That is, to obtain reflectance that is independent of scale, power-law relationship must exist (Cheng, 2008).

\section{Results}

\subsection{Upscaling reflectance analysis}

Tucker (1979), Ceccato et al. (2001) and Liang (2004), established that the visible reflectance $(400-700 \mathrm{~nm})$ is greatly influenced by leaf pigments, while leaf cell structure and biomass control the near-infrared (NIR) region (700$1300 \mathrm{~nm}$ ). Figure 2 indicates a peak reflectance centered at approximately $550-560 \mathrm{~nm}$, which is attributed to chlorophyll concentration according to Tucker et al. (1979), Ceccato et al. (2001), and Liang (2004). This peak reflectance

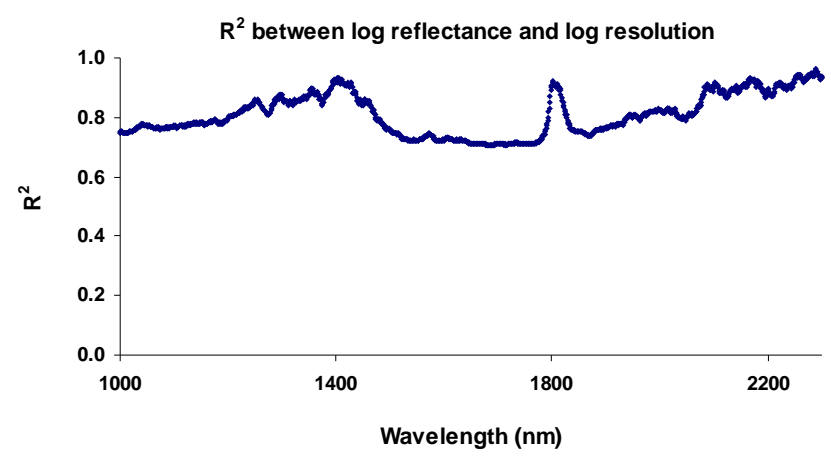

Fig. 5. $R^{2}$ between $\log$ reflectance and $\log$ resolution between $1000-2300 \mathrm{~nm}$, obtained on 12 August 2007, in site $106(n=5$, significance level $<0.05$, and critical value $R^{2}>0.65$ ).

is enhanced within the greater spatial resolutions (i.e., 31.3 to $98.5 \mathrm{~cm}$ ), while it is lower within the $11.7 \mathrm{~cm}$ scale. Since this increased reflectance is attributed to chlorophyll presence, it is possible that within the greater spatial resolutions, greater concentrations of chlorophyll are present, which in turn increase the reflectance in these scales. The reduced reflectance observed between $440-500 \mathrm{~nm}$ and $670-690 \mathrm{~nm}$ (in all scales) displays chlorophyll absorption bands, according to Liang (2004), Tucker (1979), and Campbell (1996).

As established by Ayala-Silva et al. (2005), the red edge is produced by the combination of strong absorption by chlorophyll in the red region and strong reflectance in the NIR range. This strong absorption is revealed in the $690 \mathrm{~nm}$ range, while a steep slope is observed between the red and NIR regions, at all scales (Fig. 2). Tucker (1979) and Liu et al. (2004) suggest that steep rises in reflectance of vegetation between 650 and $1100 \mathrm{~nm}$ are correlated with total chlorophyll concentration and water content. Ayala-Silva et al. (2005) established that maturity can have an impact on vegetation reflectance in the range of $500-800 \mathrm{~nm}$, where older leaves have significantly higher reflectance than young leaves. Data obtained in site 101, indicate an increased reflectance between $500-800 \mathrm{~nm}$, as the summer season is progressing (data of all sites and dates are not presented here, and are available upon request), while this pattern is not indicated in sites 103, and 106 (due to weather conditions, site 102 includes one day of measurements only). Therefore, it is possible that vegetation maturity has some influence on the reflectance obtained in this range, while, other factors (e.g., moisture availability, and chlorophyll concentrations) may influence the reflectance. In addition, the reflectance peak seen around $764 \mathrm{~nm}$ (Fig. 2) may be associated with reflectance of $\mathrm{O}_{2}$ and water, as stated by Gupta et al. (2000) and Liu et al. (2004). However, we did not conduct $\mathrm{O}_{2}$ and chlorophyll measurements since these are beyond the scope of our study. Furthermore, Tucker (1980), Ceccato et al. (2001), and Liang (2004), assert that vegetation moisture content largely controls the spectral reflectance 

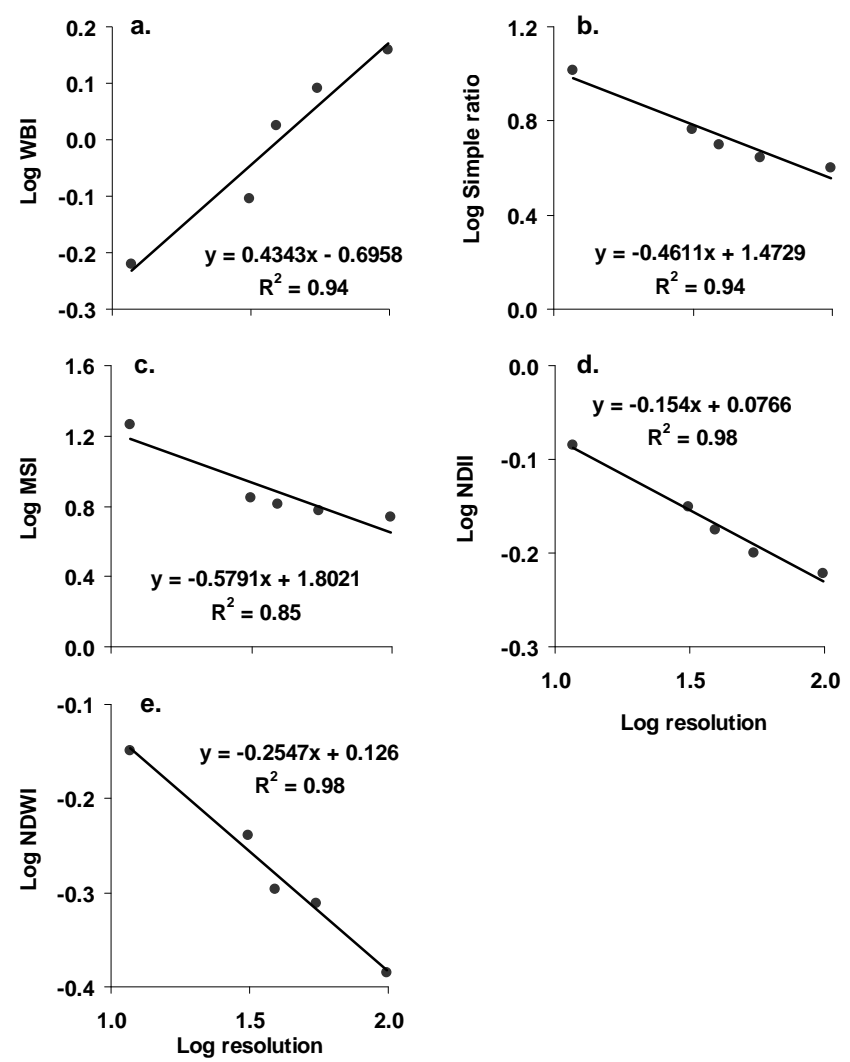

Fig. 6. Up-scaling current spectral indices; the log of the spectral indices WBI (water band index), Simple ratio, MSI (moisture stress index), NDII (normalized difference infrared index), and NDWI (normalized difference water index) are plotted against the log of the spatial resolution, in site 106 on 12 August 2007 ( $n=5$, significance level $<0.05$, and critical value $R^{2}>0.65$ ).

of the shortwave infrared (SWIR) region (1300-2500 nm). Reflectance data of our sites display several water absorption features, centered at approximately $1300 \mathrm{~nm}, 1650 \mathrm{~nm}$, and $2100 \mathrm{~nm}$ (Fig. 4).

The reflectance observed in the $400-850 \mathrm{~nm}$ and 1000 $2300 \mathrm{~nm}$ range is increasing proportionally to the spatial resolution. This increase in reflectance is emphasized between $11.7 \mathrm{~cm}$ resolution and the larger scales (i.e., $31.9 \mathrm{~cm}$, $39.2 \mathrm{~cm}, 55 \mathrm{~cm}$ and $98.5 \mathrm{~cm}$ ), while the greater scales indicate minor reflectance variations only. The higher reflectance observed in the greater scales may be related to the incident irradiance of the area; that is, the larger the area or the spatial resolution, the greater the radiance that is returned into the sensor, and so is the reflectance (Unsworth, 2008). This may also be related to the anisotropic reflection of the surface, where the reflectance is uneven at different incident angles. Other factors may also influence the higher reflectance obtained at greater scales. This may be related to various moisture conditions at different scales, as well as different distributions of vegetation species; different species may hold various quantities of water in the canopies, and the SWIR
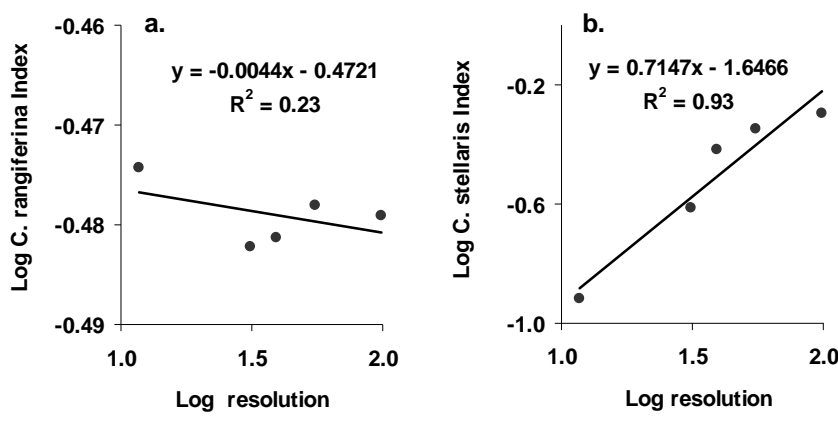

Fig. 7. Up-scaling the new spectral indices; the log of the spectral indices $C$. rangiferina (which is identical to the spectral index $D$. elongatum), and C. stellaris are plotted against the log of the spatial resolution, in site 106 on 12 August $2007(n=5$, significance level $<0.05$, and critical value $R^{2}>0.65$ ).

region is mostly influenced by moisture. In addition, variations in pigments and biomass influence both the visible and near-infrared regions.

Figures 2 and 4 indicate that the first-order derivative of the reflectance between $400-850 \mathrm{~nm}$ and $1000-2300 \mathrm{~nm}$, is matching the changes in reflectance along the electromagnetic spectrum. For example, between $460-680 \mathrm{~nm}$ and $1400-1700$, there is almost no change in the reflectance (i.e., the first-order derivative is nearly flat and close to 0 ), while a sharp change is observed between $760-770 \mathrm{~nm}$, and $1800-1900 \mathrm{~nm}$. Overall, the first-order derivative displays change in reflectance along the spectrum, while different scales present similar change in reflectance. Therefore, little information regarding change of reflectance as a result of different scales is available.

The singularity index $\alpha$ (i.e., the slope between the $\log$ of the reflectance and log of the spatial resolution, presented in Figs. 2 and 4) reveals valuable information regarding the change in reflectance as a function of changing scale. According to Cheng and Agterberg (2009), and Cheng (2008), once $\alpha=2$ the density function $\rho(\varepsilon)$ is approximately constant. Therefore, the reflectance Ref is independent of the spatial resolution $\varepsilon$. Once $\alpha<2$, the density $\rho(\varepsilon)$ is a decreasing function of $\varepsilon$, that is, Ref is reduced in smaller scales. When $\alpha>2$, the density $\rho(\varepsilon)$ is an increasing function of $\varepsilon$, and thus, may indicate greater Ref in smaller spatial resolutions $\varepsilon$. As indicated in Figs. 2 and 4, $\alpha$ (the slope between the $\log$ reflectance and the $\log$ resolution) is $<2$ for all wavelengths range (i.e., 400-850, and 1000-2300 nm). Therefore, the density $\rho(\varepsilon)$ is a decreasing function of the spatial resolution $\varepsilon$, and Ref is reduced in the smaller scales (Figs. 2 and 4).

The singularity index $\alpha$ (Figs. 2 and 4) reveals additional information regarding the change in reflectance as a result of changing scale. As $\alpha$ is increasing, so is the change in reflectance as a result of changing spatial resolution. For example, Figs. 2 and 4 indicate that $\alpha$ between 


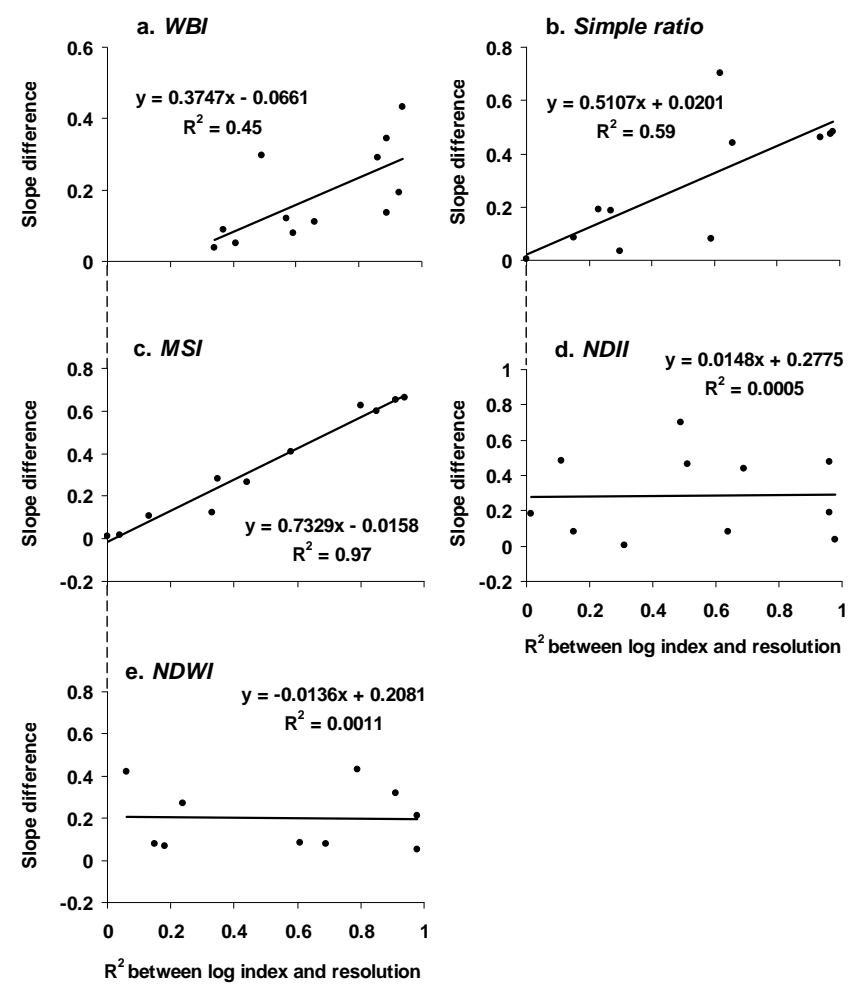

Fig. 8. The absolute difference between the slopes obtained by the wavelengths of the indices WBI (water band index), Simple ratio, MSI (moisture stress index), NDII (normalized difference infrared index), and NDWI (normalized difference water index), are plotted against the $R^{2}$ between the $\log$ of these indices and the log of the spatial resolution. These slopes are between the log reflectance and $\log$ spatial resolution obtained at the $920 \mathrm{~nm}$ and $960-1000 \mathrm{~nm}$ range for the WBI, $820 \mathrm{~nm}$ and $1600 \mathrm{~nm}$ for the Simple ratio, 1550$1750 \mathrm{~nm}$ and $760-800 \mathrm{~nm}$ range for the MSI, $820 \mathrm{~nm}$ and $1600 \mathrm{~nm}$ for the NDII, and $860 \mathrm{~nm}$ and $1240 \mathrm{~nm}$ for the NDWI $(n=11$, significance value $<0.05$, critical value $R^{2}>0.28$ ).

$500-650 \mathrm{~nm}, 700-800 \mathrm{~nm}, 1350-1450 \mathrm{~nm}, 1850-1930 \mathrm{~nm}$, and $2200-2300 \mathrm{~nm}$ is fairly small, and therefore, minor changes in reflectance are caused by different scales (Figs. 2 and 4). Moderate $\alpha$ values are displayed between 450$500 \mathrm{vnm}, 650-700 \mathrm{~nm}, 800-850 \mathrm{~nm}, 960-1350 \mathrm{~nm}, 1450-$ $1490 \mathrm{~nm}, 1800-1850 \mathrm{~nm}$, and $1930-2200 \mathrm{~nm}$. The greatest $\alpha$ values are seen between $400-450 \mathrm{~nm}$, and $1490-1800 \mathrm{~nm}$. That is, in these wavelengths, changes in reflectance are to a great extent influenced by the scale. In order to transfer information from finer to coarse resolution as accurate as possible, wavelengths with small $\alpha$ values should be considered, since minor variations in reflectance as a result of changed scale, occur in these wavelengths.

In addition to the singularity index $\alpha, R^{2}$ values between the $\log$ reflectance and the log resolution are important factors; these values can be used for evaluating whether powerlaw relationships exist $(n=5$, significance level $<0.05$, and critical value $R^{2}>0.65$ ). To determine whether the
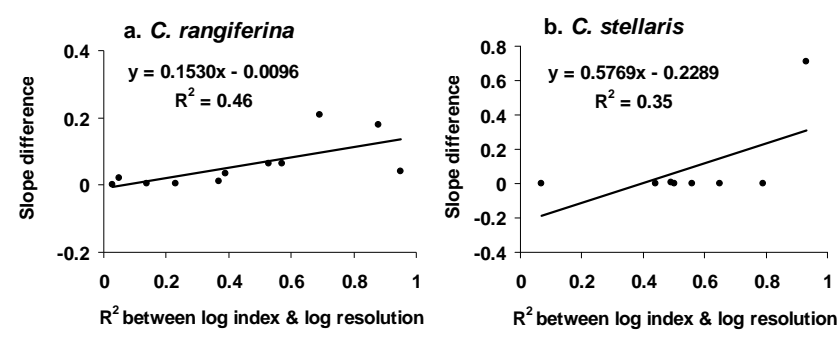

Fig. 9. The absolute difference between the slopes obtained by the wavelengths of the new species specific indices $C$. rangiferina and C. stellaris, are plotted against the $R^{2}$ between the log of these indices and the $\log$ of the spatial resolution. These slopes are between the $\log$ reflectance and log spatial resolution obtained at the $1080 \mathrm{~nm}$ and $1480 \mathrm{~nm}$ range for $C$. rangiferina index, and $900 \mathrm{~nm}$ and $1470 \mathrm{~nm}$ for the $C$. stellaris index $(n=11$, significance value $<0.05$, critical value $R^{2}>0.28$ ).

reflectance is independent of scale, power-law relationship must exist (Cheng, 2008). The coefficient of determinations $\left(R^{2}\right)$ between the log reflectance and the log spatial resolution were plotted for the $400-850 \mathrm{~nm}$ (Fig. 3) and the $1000-2300 \mathrm{~nm}$ regions (Fig. 5). If the data follow powerlaw relationships (i.e., $R^{2}>0.65$ then the slope between $\log$ reflectance and $\log$ resolution may indicate the degree of non-linearity; great $R^{2}$ values have fewer errors, while reduced $R^{2}$ values denote that slope calculations are inaccurate. Overall, it is indicated that $R^{2}$ values of both 450 $850 \mathrm{~nm}$ (Fig. 3) and 1000-2300 nm (Fig. 5) regions of the spectrum, are significant $\left(R^{2}>0.65\right)$. These suggest that since power-law relationships exist, the calculation of the slope contain few errors.

\subsection{Up-scaling spectral reflectance indices}

Seeing as this study serves as a basis for future aircraft/satellite studies, an attempt to upscale current spectral reflectance indices (i.e., WBI, Simple ratio, MSI, NDII, and NDWI) along with the new species specific spectral indices (i.e., C. stellaris and C. rangiferina) developed in our previous studies (Neta et al., 2010a, b) was made. Figures 6-7 present an example of these spectral indices at various scales, obtained in site 106, on 12 August 2007. For upscaling plants' moisture content from finer to coarser resolutions it is suggested to use an index that is independent of scale. That is, the $R^{2}$ values of such index will be nearly or equal to 0 . Alternatively, the slope between the index values and the spatial resolution will be small or close to 0 .

The $R^{2}$ and the slope between the log of the indices and the log of the spatial resolution were analyzed to examine the relationship between the spectral indices and the scale (Figs. 6-7). That is, to what extent do these indices change as a result of varying scales. Furthermore, the slope between the $\log$ of the reflectance and the $\log$ of the spatial resolution (i.e., the singularity index $\alpha$; Figs. 2 and 4) was examined 
whether wavelengths applied in these indices have similar $\alpha$ values, and how is it related to the scale.

The mean $R^{2}$ values (of all sites and dates) between the $\log$ of these spectral indices and the log of the spatial resolution are in the following increasing order: $C$. rangiferina (0.44), MSI (0.49), Simple ratio (0.52), NDII (0.54), C. stellaris (0.55), NDWI (0.55), and the WBI (0.67). According to these results, the spectral index $C$. rangiferina is less influenced by scale. The mean slopes (for all sites and dates) between the log of the above spectral indices and the log of the spatial resolution are in the following increasing order: MSI (-0.286), Simple ratio ( -0.1774$)$, NDWI $(-0.0599)$, C. stellaris (-0.0534), WBI (0.106), NDII (0.119), and $C$. rangiferina (0.2717). In this case, the $C$. stellaris index is less influenced by scale, as this value is the closest to 0 .

In order to examine the above indices in terms of scale independence, $\alpha$ values (presented in Figs. 2 and 4) of each wavelength (or wavelength range) of the above indices, was analyzed. The absolute difference values (i.e., subtraction) between the $\alpha$ values of two wavelength (or wavelength range) of each spectral index, are plotted against the $\mathrm{R}^{2}$ between the log of these indices and the log of the spatial resolution (Figs. 8-9).

The general trend observed in Figs. 8-9 (with the exception of the indices NDII and NDWI) is that as the absolute difference in $\alpha$ values is reduced, so is the $R^{2}$ between the $\log$ of these indices and the log of these spatial resolutions. That is, as $\alpha$ values of two wavelengths (or wavelength range) employed by each index become similar, the $R^{2}$ between these indices and the spatial resolution is reduced; a ratio between the reflectance of two wavelengths with similar $\alpha$ values is neutralizing the scale effect. Therefore, as $\alpha$ values become similar, the spectral index is less influenced by scale; at different scales the results of these spectral indices are similar, and thus these indices are independent of scale. As a result, an index that is less influenced by scale is one that includes two wavelengths with similar $\alpha$ values.

It can be summarized that an index that is less influenced by scale will have small $R^{2}$ values between the log of the reflectance and the log of the resolution, reduced slopes between the $\log$ of the index and the log of the resolution, and similar $\alpha$ values of the two wavelengths employed by the index. This analysis may help define indices that are scale independent.

Of the new spectral indices, it was found that the wavelengths employed by $C$. rangiferina index (Table 1), have similar slopes versus those of the $C$. stellaris index, and as a result, the values of the $C$. rangiferina index are to a lesser amount affected by the scale. Furthermore, as indicated in our previous study (Neta et al., 2010a), the $C$. rangiferina index improved moisture content detection of both species $C$. rangiferina and D. elongatum. Therefore it is suggested to use this index for upscaling purposes.

\section{Summary and conclusions}

Monitoring moisture conditions of lichens and mosses along with the water-table position by remote sensing technology may provide valuable information for present and future carbon balance modeling. However, previous studies are based upon point measurements of vegetation moisture content and water table position. These measurements cannot describe moisture conditions of northern peatlands over large spatial scale, and consequently, upscaling ground and remotely sensed data to the desired spatial resolutions is inevitable. The results of this study suggest the following:

1. The singularity index $\alpha$ is $<2$ for all wavelengths range (i.e., $400-850$, and $1000-2300 \mathrm{~nm}$ ), indicating that the reflectance is reduced in the smaller scales. The higher reflectance observed in the greater scales may be related to the incident irradiance of the area, or the anisotropic reflection, as well as the vegetation distribution, vegetation density, vegetation pigments, moisture content and biomass.

2. The coefficient of determinations $\left(R^{2}\right)$ between the log reflectance and log resolution can be used for evaluating whether power-law relationships exist. If the data follow power-law relationships (i.e., $R^{2}>0.65$ ), then $\alpha$ may indicate the degree of non-linearity; great $R^{2}$ values have fewer errors, while reduced $R^{2}$ values denote that slope calculations are inaccurate. $R^{2}$ values between $450-850 \mathrm{~nm}$, and $1000-2300 \mathrm{~nm}$ are significant (i.e., $R^{2}>0.65$ ). These suggest that the calculation of the slope contains few errors.

3. An index that is independent of scale is expected to have small $R^{2}$ values between the index values and the resolution, small $R^{2}$ values between the log of the index and the $\log$ of the resolution, reduced slopes between the $\log$ of the index and the $\log$ of the resolution, and similar $\alpha$ values of two wavelengths employed by the index. Of all spectral indices studied here, it was found that the spectral index $C$. rangiferina is to a lesser amount. influenced by scale. In addition, $C$. rangiferina index improved moisture content detection of both $C$. rangiferina and D. elongatum, and therefore it is suggested to use this index for upscaling purposes.

4. Future research should focus on concurrent monitoring of moisture variations in lichens and mosses both in situ and from satellite and airborne images, as well as analysis of fractal models in relations to our upscaling experiments. 
Acknowledgements. The authors thank the Churchill Northern Studies Centre (CNSC) for granting access to the Hudson Bay Lowlands study sites and laboratory facilities. Sarah Verma is thanked for assistance with laboratory and field experiments. The ground-based spectrometers were generously supplied by Professor John Miller of the Department of Earth and Space Sciences and Engineering, and the Geography Department of York University. This work was funded by the NSERC Northern Internship, Northern Research Fund (NRF) of the CNSC, Northern Scientific Training Program (NSTP), as well as the Fieldwork Costs Fund, and Research Costs Fund of York University.

Edited by: A. M. Tarquis

\section{References}

Ayala-Silva, T. and Beyl, C. A.: Changes in spectral reflectance of wheat leaves in response to specific macronutrient deficiency, Adv. Space. Res., 35, doi:10.1016/j.asr.2004.09.008, 305-317, 2005.

Bubier, J. L., Rock, B. N. and Crill., P.M.: Spectral reflectance measurements of boreal wetland and forest mosses, J. Geophy. Res., 102 (D24), 29483-29494, 1997.

Campbell, J. B.: Introduction to Remote Sensing, The Guilford Press, New York, 1996.

Ceccato, P., Flasse, S., Tarantola, S., Jacquemound, S. and Gregoire, J.: Detecting vegetation leaf water content using reflectance in the optical domain, Remote. Sens. Environ., 77(1), 22-33, 2001.

Chen, J. M.: Spatial scaling of a remotely sensed surface parameter by contexture, Remote. Sens. Environ., 69(1), 30-42, 1999.

Cheng, Q.: A new model for incorporating spatial association and singularity in interpolation of exploratory data, in: Geostatistics Banff 2004, Quantitative Geology and Geostatistics, 14, edited by: Leuangthong, D. and Deutsch, C. V., Springer, New York, 1017-1026, 2006.

Cheng, Q.: Modeling Local Scaling Properties for Multiscale Mapping, Vadose. Zone. J., 7(2), 525-532, 2008.

Ehleringer, J. R. and Field, C. B.: Scaling physiological processes: Leaf to globe, Academic Press, 1993.

El Maayar, M. and Chen., J. M.: Spatial scaling of evapotranspiration as affected by heterogeneities in vegetation, topography, and soil texture, Remote. Sens. Environ., 102, 33-51, 2006.

Gao, B.: NDWI - A Normalized difference water index for remote sensing of vegetation liquid water from space, Remote. Sens. Environ., 58(3), 257-266, 1996.

Gupta, R. K., Vijayan, D., and Prasad, T. S.: Spectral signature variations as a function of bandwidth using $3 \mathrm{~nm}$ bandwidth observations, Adv. Space. Res., 267, 1145-1148, 2000.

Hardisky, M. A,, Klemas, V., and Smart, R. M.: The influence of soft salinity, growth form, mad leaf moisture on the spectral reflectance of Spartina alterniflora canopies, Photogramm. Eng. Rem. S., 49(1), 77-83, 1983.

Hay, G. J., Niemann, K. O., and Goodenough, D. G.: Spatial thresholds, image-objects, and upscaling: A multiscale evaluation, Remote. Sens. Environ., 62(1), 1-19, 1997.
Liang, S.: Canopy reflectance modeling, in: Quantitative remote sensing of land surfaces, edited by: Hoboken, N. J., WileyInterscience, 76-142, 2004.

Liu, L., Wang, J., Huang, W., Zhao, C., Zhang, B., and Tong Q.: Estimating winter wheat plant water content using red edge parameters, Int. J. Remote Sens., 25(17), 3331-3342, 2004.

Neta, T., Cheng, Q., Bello, R., and Hu, B.: Development of new spectral reflectance indices for the detection of lichens and mosses moisture content in the Hudson Bay Lowlands, Canada, Hydrol. Process., Manuscript ID:HYP-10-0086.R1, 36 p, accepted, in progress., 2010a.

Neta, T., Cheng, Q., Bello, R., and Hu, B.: Lichens and mosses moisture content assessment through high-spectral resolution remote sensing technology: A case study of the Hudson Bay Lowlands, Canada, Hydrol. Process., doi:10.1002/hyp.7669, 12 p, 2010 b.

Penuelas, J., Pinol, J., Ogaya, R., and Fiella, I.: Estimation of plant water concentration by the reflectance water index WI (R900 /R970), Int. J. Remote Sens., 18(13), 2869-2875. doi:10.1080/014311697217396, 1997.

Ricketts, T. H., Dinerstein, E., Carney, K., Abell, R. A. and Walters, S.: Terrestrial Ecoregions of North America: A Conservation Assessment, Island Press, 1999.

Sanderson, E. W., Zhang, M., Ustin, S. L., and Rejmankova, E.: Geostatistical scaling of canopy water content in a California salt marsh, Landscape. Ecol., 13(2), 79-92, 1998.

Simic, A., Chen, J. M., Liu, J., and Csillag, F.: Spatial scaling of net primary productivity using subpixel information, Remote. Sens. Environ., 93 (1-2), 246-258, 2004.

Tucker, C. J.: Red and photographic infrared linear combinations for monitoring vegetation, Remote. Sens. Environ., 8(2), 127$150,1979$.

Tucker, C. J.: Remote sensing of leaf water content in the near infrared, Remote. Sens. Environ., 10(1), 23-32. 1980.

University of Maine Canadian-American Center Cartography: www.umaine.edu/canam/teachingcanada.htm, 2005.

Unsworth, M. K.: Principles of environmental physics, Elsevier, Amsterdam, Boston, 418 p, 2008.

Vogelmann, J. E. and Rock, B. N.: Assessing forest decline in coniferous forests of Vermont using NS-001 Thematic Mapper simulator data, Int. J. Remote Sens., 7(10), 1303-1321, 1986.

Walter, B. P., Heimann, M., and Matthews, E.: Modelling modern methane emissions from natural environments: 1 . Model description and results, J. Geophys. Res., 106(D24), 34189-34206, 2001.

Wang, G., Gertner, G. Z., and Anderson, A. B.: Spatial-VariabilityBased Algorithms for scaling-Up Spatial Data and Uncertainties, IEEE. T. Geosci. Remote., 42(9), 2004-2015, 2004.

Williams, M., Bell, R., Spadavecchia, L., Street, L. E., and Van Wijk, M. T.: Upscaling leaf area index in an Arctic landscape through multiscale observations, Glob. Change. Biol., 14(7), 1517-1530, 2008.

Wu, J. and Qi, Y.: Dealing with scale in landscape analysis: An overview, Geographic Information Sciences, 6, 1-5, 2000. 